Arh. hig. rada toksikol., 30 (1979) suppl. pp. 1301-1322.

\title{
EFFECT OF IMPERMEABLE CLOTHING AND RESPIRATOR ON WORK PERFORMANCE
}

\author{
H.A. ATTERBOM and P.B. MOSSMAN \\ University of New Mexico and Sandia Laboratories, Albuquerque, New Mexico, U.S.A.
}

\section{ABSTRACT}

The use of impervious clothing and respirators in various industries, including atomic energy, can be expected to increase in the future. Most studies in the past have been concerned with low levels of work intensity. The work intensities used in this study were dictated by the energy requirements of emergency decontamination tasks which could, occasionally, demand near-maximal effort.

The effect of vapor barrier protective clothing (VBC) as studied in seven subjects during maximal and submaximal work $\left(60^{\circ} \ldots \mathrm{V}_{0}\right)$ is described. During rest, most of the heat is dissipated through convection and radiation. However, during exercise, evaporation becomes progressively more important in maintaining thermal cquilibrium. Vapor barrier clothing interferes with this important aspect of thermoregulation.

At submaximal work loads $\left(60 \% \mathrm{~V}_{0}\right)$ total work production was reduced from $75000 \mathrm{kpm}$ without VBC to $27000 \mathrm{kpm}$ or $64 \%$. Mean exercise heart rate (HR) increased from 139 to $159 \mathrm{bpm}$ and tolerance time was reduced by $63^{\circ}$ o from $101 \mathrm{~min}$ to $39 \mathrm{~min}$.

At maximal work loads ( $\mathrm{Max} \mathrm{V}_{\mathrm{O}}$ ), VBC resulted in an $11 \%$ reduction in tolerance time $(19.6$ $\min$ to $17.4 \mathrm{~min}$ ) and, more significantly, a decrease in work output from $15100 \mathrm{kpm}$ to 11800 kpm.

For the brief work periods ( $\mathrm{Max} \hat{V}_{0}$ ), HR appears to be the preferred stress indicator. However, in VBC, skin temperature $\left(\bar{T}_{5}\right)$ correlated well with HR. During prolonged work, $T_{r}$ correlated with HR when VBC was not worn, whereas, with VBC $\bar{T}$, provided a more accurate stress measure.

The increase in skin temperature observed with the tests in VBC can only be explained by a large cutaneous shunting of blood under conditions of curtailed heat dissipation. This results in a reduction of cardiac output distribution to metabolically active tissues, particularly muscle, and best explains the decrease in both tolerance time and total work output. It imposes on the organism a physiological stress of considerable magnitude. This stress cannot be ignored in any work situation requiring over a $40^{\circ}$, maximum effort while subjects are clothed in VBC with respirators.

The hazards of work in impermeable clothing have been documented in the past. With the growth of the chemical industry and now the projected increase in atomic energy usage, it becomes important to recognize what effects these suits have on work performance and also to what extent significant stress is produced.

The requests for reprints should be sent to: Paul B. Mossman, M.D., Medical Director, Sandia Laboratories, P.O. Box 5800. Albuquerque, New Mexico, 87185 , U.S.A. 
Ideally, tolerance times for different levels of activity or work should be developed. The present study can only be regarded as a preliminary step in this direction.

The following equation describes in simplified terms the complex relationship of heat balance between man and his environment:

$$
\mathrm{M} \pm \mathrm{C} \pm \mathrm{R}-\mathrm{E}= \pm \mathrm{S}
$$

where $\mathrm{M}=$ heat of metabolism (including work); $\mathrm{C}, \mathrm{R}=$ heat gained or lost by convection, radiation; $\mathrm{E}=$ heat lost by evaporation of sweat; $\mathrm{S}=$ total heat gained or lost by the body (when the body is in thermal equilibrium, $\mathrm{S}=0$ ).

While the subject is working in a plastic suit, heat loss from evaporation is negligible. Therefore, heat storage occurs and this thermal imbalance results in profound changes in human physiology. It is with these changes that much of this report is concerned.

The experimental literature does provide some assistance in attempting to answer our earlier questions regarding quantitation of risks. Figure 1 provides an example of tolerance times under varying conditions of work, clothing, and environmental temperatures ${ }^{3}$. The data were obtained from an experiment which was designed to test a two-layer protective uniform, not a plastic impermeable suit. The first layer was standard U.S. Army fatigue gear, and the second was made of a relatively impermeable cloth material. The WBGT index is calculated

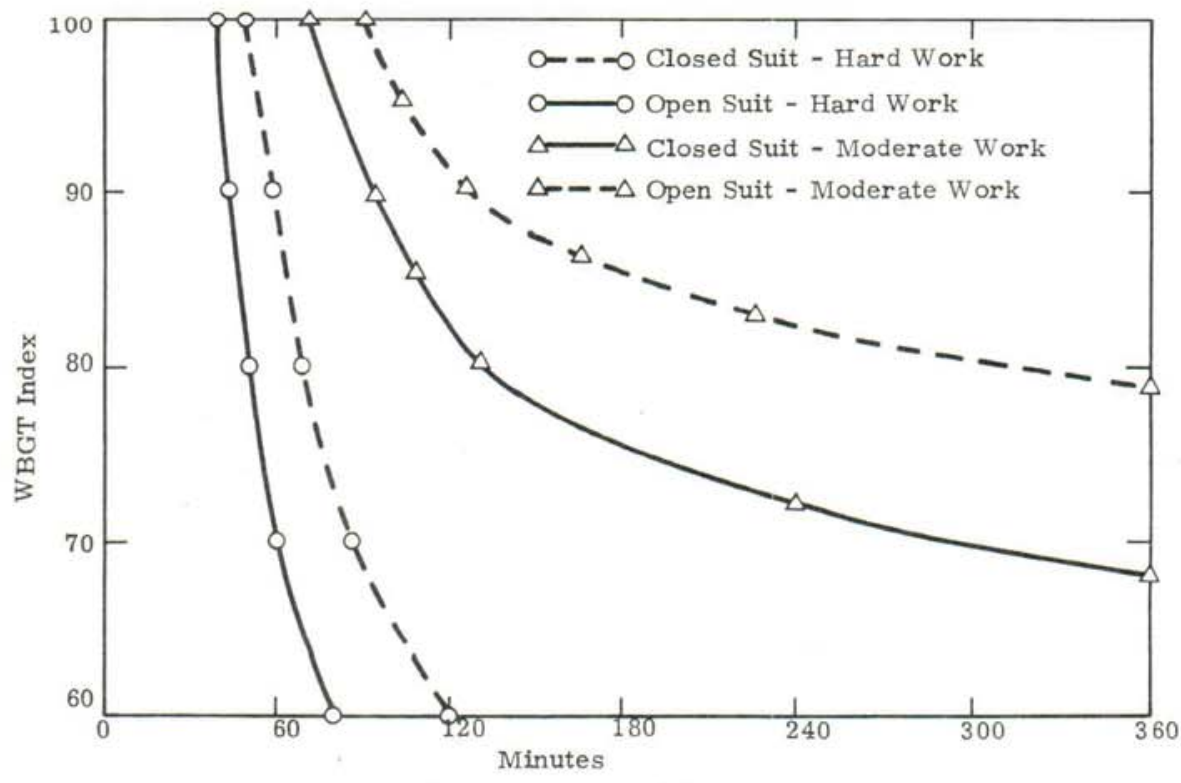

FIG. 1 - Predicted time to $50^{\circ}$. heat casualties. 
as $0.7 \times$ wetbulb temperature $+0.2 \times$ black-globe temperature (radiant) +0.1 $x$ shaded dry-bulb temperature and provides a way to predict heat stress produced by various climatic variables 8 . For example, at a WBGT index of $30^{\circ} \mathrm{C}$, troops in conventional uniforms should have decreased training regimens, and an index of 100 necessitates cessation of all physical training activities?

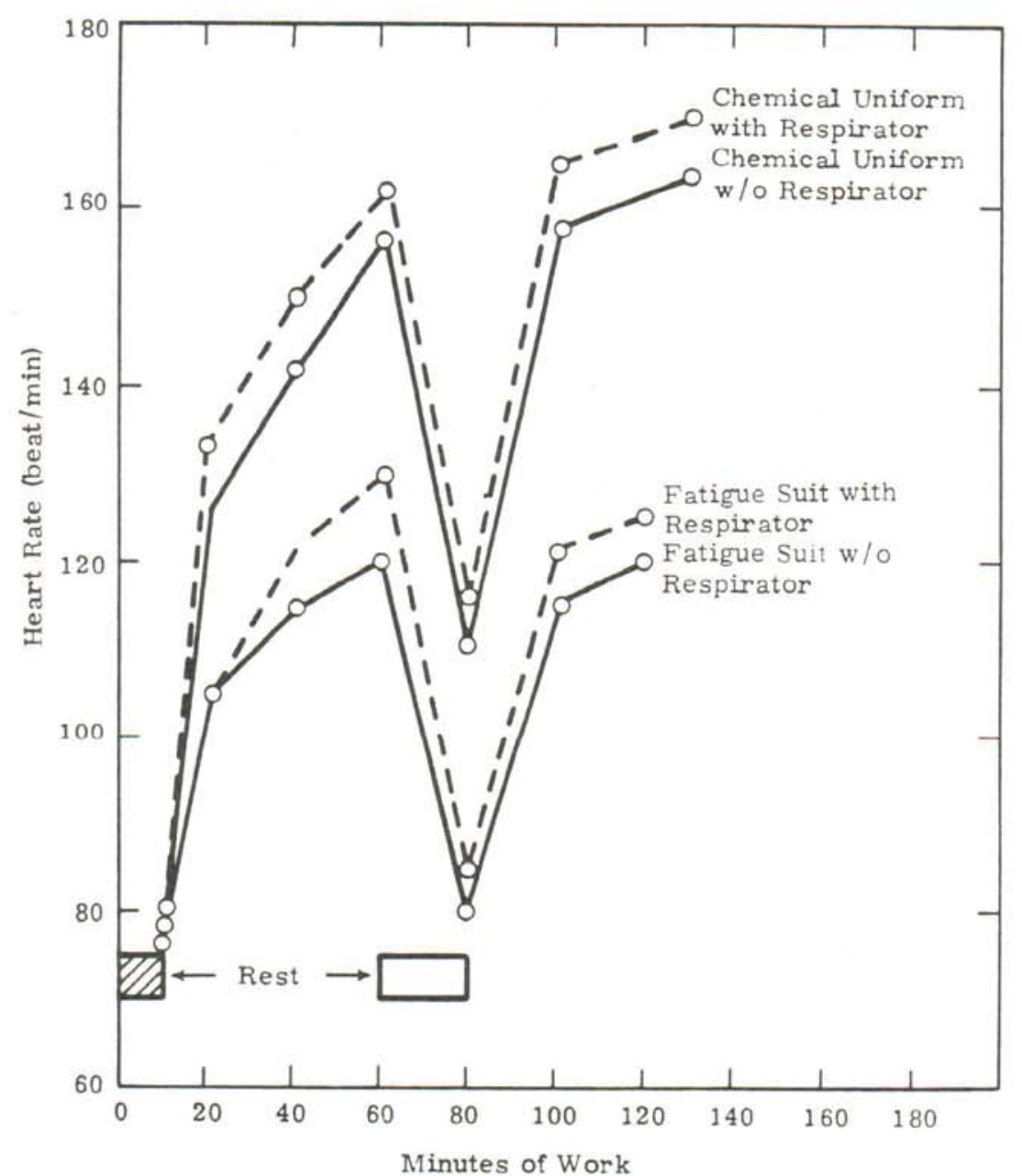

FIG. 2 - Effect on heart rate of clothing and respirator at constant work load and temperature.

Figure 2 shows that, in addition to the stress induced by plastic, impermeable suits, protective face masks have also contributed to performance decrements which have been attributed to "the additional respiratory load imposed from breathing against the resistance of the mask, and to the reduced 
heat loss which results from covering the face with an impermeable material" 6 . This experiment was conducted with four different uniforms at constant work load and climate. In addition to the difference in heart rate (HR), significant differences in sweat rate and rectal temperature were recorded. It was observed that the increase in HR could not be attributed solely to the changes in body temperature. The stress of the respirator increased directly with work time.

\section{METHODS AND PROCEDURES}

\section{Subjects}

Seven healthy, well-conditioned males served as subjects (Ss) on a volunteer basis. Ss were acclimatized to moderately high altitude through continuous residence in central New Mexico for a minimum period of 15 months; all but one $\mathrm{S}(\mathrm{CH})$ had resided in the Albuquerque area for more than 3 years. Pertinent $\mathrm{S}$ data are presented in Table 1. Mean age was 28.9 years (range 20.3 to 45.5 ) and mean maximal $\hat{\mathrm{V}}_{\mathrm{O}_{2}}$ was $47 \mathrm{ml} \times \mathrm{kg}^{-1} \times \min ^{-1}$ (range 36 to 55 ). Ss had been selected on the basis of their high level of regular physical activity.

TABLE 1

Selected subject data.

\begin{tabular}{|c|c|c|c|c|c|c|c|}
\hline Subject & $\begin{array}{l}\mathrm{Age} \\
(\mathrm{yr})\end{array}$ & $\begin{array}{l}\text { Height } \\
(\mathrm{cm})\end{array}$ & $\begin{array}{l}\text { Weight } \\
\text { (kg) }\end{array}$ & $\begin{array}{l}\text { BSA } \\
\left(m^{2}\right)\end{array}$ & $\begin{array}{c}\mathrm{Max} \mathrm{V}_{\mathrm{O}_{2}} \\
\left(\mathrm{ml} \times \mathrm{kg}^{-1}\right. \\
\left.\times \min ^{-1}\right)\end{array}$ & Activity & Ethnic group \\
\hline AA & 45.5 & 178.8 & 79.4 & 1.98 & 47 & Runner & Caucasian \\
\hline RC & 22.2 & 163.5 & 56.3 & 1.63 & 55 & W restler & Caucasian \\
\hline $\mathrm{CH}$ & 33.3 & 178.8 & 81.5 & 2.05 & 45 & Bicyclist & Caucasian \\
\hline AJ & 29.0 & 175.1 & 77.9 & 1.94 & 36 & Jogger & Afro-American \\
\hline $\mathrm{AM}$ & 22.1 & 158.7 & 53.0 & 1.52 & 47 & Jogger & Spanish-American \\
\hline LM & 20.3 & 175.3 & 58.6 & 1.70 & 54 & Runner & Navajo Indian \\
\hline $\mathrm{JT}$ & 29.8 & 185.6 & 81.6 & 2.07 & 43 & Jogger & Caucasian \\
\hline $\bar{x}$ & 28.9 & 173.7 & 69.8 & 1.84 & 47 & & \\
\hline S.D. & 8.8 & 9.4 & 13.1 & 0.22 & 6 & & \\
\hline
\end{tabular}

\section{Clothing}

The impervious clothing, referred to in this report as vapor-barrier clothing (VBC), consisted of a full-body cotton coverall, thin rubber boots, plastic pants and hooded jacket*, rubber gloves, and a full-face air purification system**. All seams between clothing articles were sealed with plastic tape to produce a virtually airtight outer layer of protective clothing (this is illustrated in Figure 3). Underneath this clothing were the items used during the control tests: cotton shorts, tube socks, and jogging shoes. The dry weight of the VBC was $4.1 \mathrm{~kg}$.

-Two-piece suit with hood of 0.004 in polysinyl chloride with elastic at wrixt. ankles, and waist.

-NSA Ultravue facepicee with type GNR-S chin-style gas mask canister. 


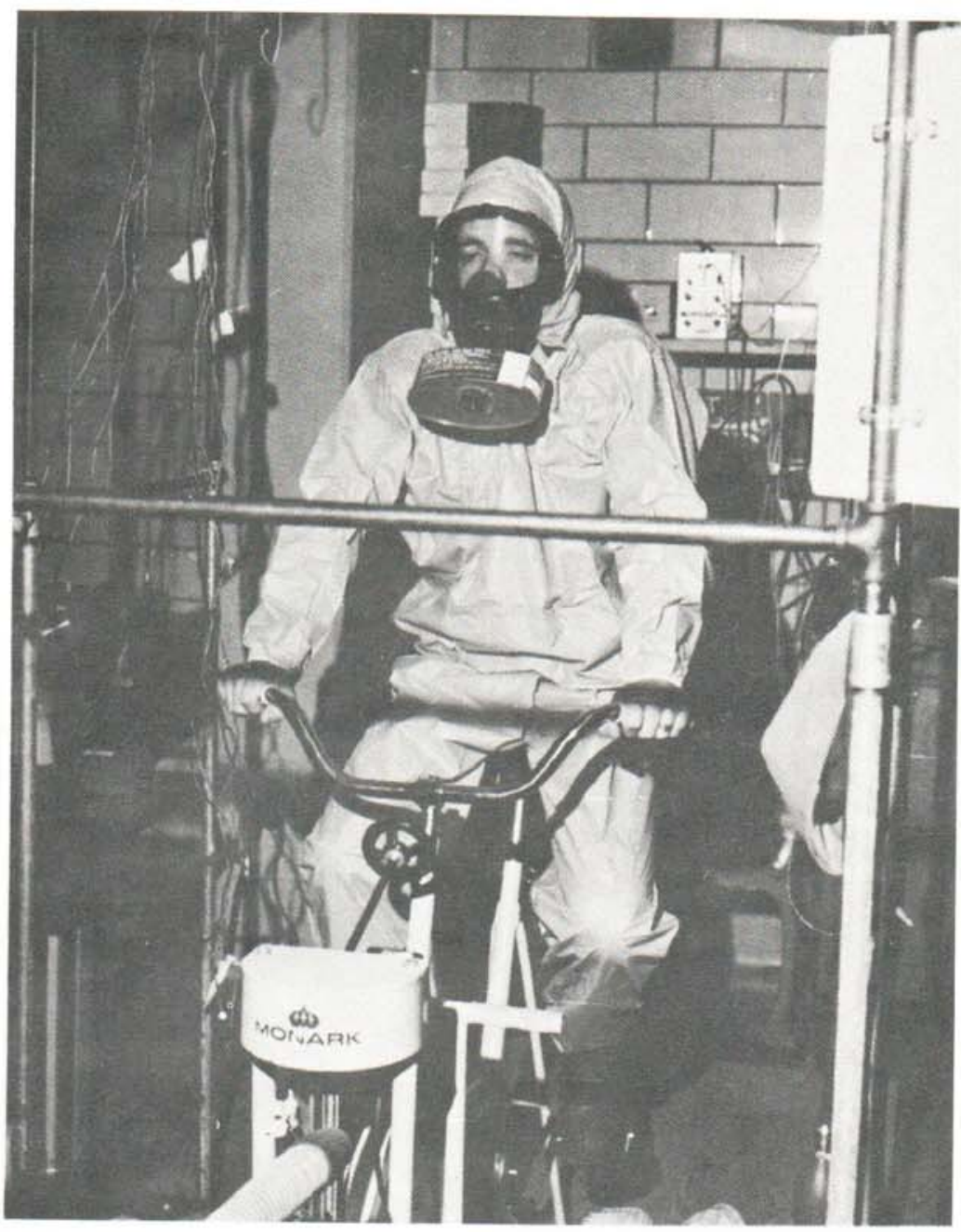

FIG. 3 - The vapor-barrier clothing (VBC) worn for the tests (except that this subject is not wearing the gloves or rubber boots).

Testing

Four different exercise testing protocols were administered to each of the 7 Ss, namely tests $1,2,3$, and 4 . In addition, tests 5 and 6 were administered to the other four (Table 2). Tests were not assigned in the same order for every $\mathrm{S}$, although randomization was impossible since some testing protocols were predicated upon the results of others. All Ss were tested between 10:00 and $12: 00$ a.m. and subsequent tests were performed with a minimum intervening time period of 48 hours. 
TABLE 2

Test protocols.

\begin{tabular}{|c|c|c|c|}
\hline Test & Clothing & Profile & Load \\
\hline 1 & Shorts & Progressive maximal effort & Multistage to maximal \\
\hline 2 & VBC & Progressive maximal effort & Multistage to maximal \\
\hline 3 & Shorts & Prolonged submaximal work & $\begin{array}{l}\text { Multistage to } 60^{\circ} \text { of maximal, } \\
\text { then to exhaustion at } 60^{\circ} \text {. }\end{array}$ \\
\hline 4 & VBC & Prolonged submaximal work & $\begin{array}{l}\text { Multistage to } 60^{\circ} \text { of maximal, } \\
\text { then to exhaustion at } 60^{\circ} \text {. }\end{array}$ \\
\hline 5* & Shorts & Square-wave maximal effort & $90-95^{\circ}$ of maximal to exhaustion \\
\hline $6^{*}$ & VBC & Square-wave maximal effort & $90-95 \%$ of maximal to exhaustion \\
\hline
\end{tabular}

- Pertormed by four Ss (AA, CH, A). IT

Mean dry-bulb temperature was $25.3^{\circ} \mathrm{C}$ and mean relative humidity was $15 \%$.

Exercise stress tests were performed on a Monark mechanically braked bicycle ergometer adjusted according to Ástrand ${ }^{1}$. The pedalling rate was $60 \mathrm{rpm}$ and pace was governed by an electrical metronome.

Tests 1 and 2 were multistage, maximal tests of the modified Balke type (Figure 4a). The load for the initial 3 minutes was $90 \mathrm{kpm} / \mathrm{min}$, whereafter it was augmented at the end of each minute of exercise by step-wise increases of 90 $\mathrm{kpm} / \mathrm{min}$. Tests were continued until the S's maximum was reached.

Tests 5 and 6 were also maximum efforts, but the maximum load was reached suddenly instead of progressively. Near-maximum load was applied directly after a 5 minute warm-up period (Figure $4 \mathrm{~b}$ ). The warm-up load was 90 $\mathrm{kpm} / \mathrm{min}$ for the first 3 minutes, followed by $360 \mathrm{kpm} / \mathrm{min}$ for the next 2 minutes. Thereafter, the load was abruptly increased to a predetermined intensity

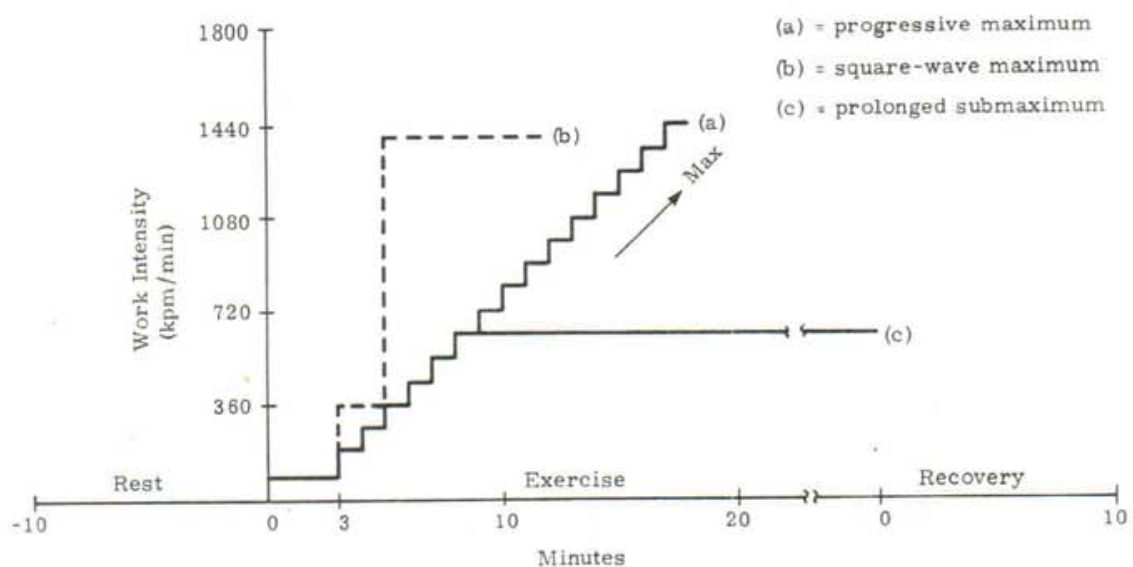

FIG. 4 - Ergometer test profiles. 
designed to demand a $\mathrm{V}_{\mathrm{O}_{2}}$ of about $95 \%$ of maximum. The actual load was 93 to $96 \%$ and was maintained until exhaustion.

Tests 3 and 4 were submaximum exercises at constant loads initially reached through a multistage protocol. They were predetermined to demand about $60^{\circ} \%$ of maximum.

Tests 1, 3, and 5 were performed in shorts and tests 2,4 , and 6 while the VBC was worn. The submaximum tests ( 3 and 4 ) were continued until either of the following occurred: (1) HR approaching maximum, (2) objective signs of severe discomfort or fatigue, or (3) subjective perceptions of inability to proceed. Had any S's rectal temperature exceeded $40.5^{\circ} \mathrm{C}$, tests would also have been terminated, but this did not occur. The maximum tests $(1,2,5$, and 6$)$ were terminated when $\mathrm{Ss}$ could no longer maintain prescribed pedalling rate despite intense verbal encouragement.

\section{Procedure}

HR was recorded throughout the test for 15 seconds of each minute electrocardiographically by telemetry with two skin electrodes. Expired air was collected during the 3 minute pre-exercise period and the last 30 seconds of each collection minute during exercise. For the maximal tests $(1,2,5$, and 6$)$ collection began when HR reached 125 to 130 beat/min and was repeated thereafter every other minute until subjects approached maximum effort. At that time, collection took place every minute until termination. Expired air was collected in Douglas bags, and with marked exertion, meteorological balloons with a low resistance valve.

For the submaximal tests ( 3 and 4 ) a similar procedure was followed except that $\mathrm{HR}$ and temperatures were recorded every 5 minutes and expired air every 10-15 minutes.

Each subject was weighed naked before and after exercise. Skin $\left(\overline{\mathrm{T}}_{\mathrm{s}}\right)$ and rectal $\left(T_{r}\right)$ temperatures were recorded with a telethermometer system. A rectal probe was inserted to a depth of $15 \mathrm{~cm}$ and four skin sensors were located on the forehead, mid-chest, the dorsal aspect of the right, wrist, and the lateral surface of the lower right leg about $5 \mathrm{~cm}$ below the knee.

\section{RESULTS AND DISCUSSION}

Effects of the VBC on maximal performance

Progressive maximal effort

Table 3 shows selected data recorded during maximal exercise which had been attained through a protocol of gradually increasing work loads (tests 1 and 2). Without the VBC, the Ss endured for 17 to 25 minutes as compared to 13 to 20 minutes when the VBC was worn. Mean tolerance times were 19.6 minutes and 17.4 minutes, respectively, for a decrease of $11 \%$.

Maximum power output was decreased by about $13 \%$ which, in addition to the shorter tolerable work time, resulted in a $22 \%$ reduction in total work. Total 
TABLE 3

Mean maximal data recorded during maximal effort reached through a progressive test (mean \pm S.D.).

\begin{tabular}{llccc}
\hline Variable & Unit & Without VBC & With VBC & $\begin{array}{c}\text { Difference } \\
\text { (\%) }\end{array}$ \\
\hline Time & min & $19.6 \pm 2.6$ & $17.4 \pm 2.4$ & -11 \\
Power & $\mathrm{kpm} / \mathrm{min}$ & $1594 \pm 263$ & $1389 \pm 213$ & -13 \\
& watt & $201 \pm 43$ & $227 \pm 35$ & -13 \\
Total work & $\mathrm{kpm} \times 10^{-3}$ & $15.1 \pm 4.6$ & $11.8 \pm 3.2$ & -22 \\
$\hat{V}_{\mathrm{O}_{2}}$ & $\mathrm{ml} / \mathrm{kg}$ min & $45.6 \pm 8.2$ & $42.9 \pm 4.1$ & -6 \\
$\mathrm{HR}$ & $1 / \mathrm{min}, \mathrm{STPD}$ & $3.11 \pm 0.53$ & $2.96 \pm 0.48$ & -5 \\
\hline & beat $/ \mathrm{min}$ & $180.3 \pm 12.2$ & $181.0 \pm 11.3$ & 0.5 \\
\hline
\end{tabular}

work without the VBC was $15100 \mathrm{kpm}$ as compared to $11800 \mathrm{kpm}$ with the VBC.

Mean maximum HR was identical under both test conditions which validates the maximum effort. Maximal $\hat{\mathrm{V}}_{\mathrm{O}_{2}}$ was reduced by $8.5 \%$ when the $\mathrm{VBC}$ was worn. This is explained by a decreased perfusion of the metabolically active, working muscles due to a redistribution of cardiac output (Q) to more peripheral, heat-dissipating areas.

Figure 5 shows that, after a few minutes of work, both skin and rectal temperatures increased. After 13 minutes of work, $\mathrm{T}_{\mathrm{r}}$ rose by $0.033^{\circ} \mathrm{C}$ per minute of work. $\overline{\mathrm{T}}_{\mathrm{s}}$, after 8 minutes of work, showed a minute increase of $0.133^{\circ} \mathrm{C}$. The mean temperatures at exhaustion were $\mathrm{T}_{\mathrm{r}}=37.40^{\circ} \mathrm{C}$ and $\overline{\mathrm{T}}_{\mathrm{s}}=36.40^{\circ} \mathrm{C}$. Neither of these even approach maximal values. Therefore, the work time was apparently too brief for either $T_{r}$ and $\bar{T}_{S}$ to reach critical levels and, consequently, their usefulness as tolerance predicators during maximum work effort is not documented in this study.

As seen in Figure 6, HR increased linearly with work intensity, both with and without the VBC. At any given work intensity, HR was 15 to $20 \mathrm{beat} / \mathrm{min}$ higher when the VBC was worn. Thus, HR would appear to be a satisfactory stress indicator during high-intensity work in heat-insulating clothing.

Sudden maximal effort

It should be noted that the maximal power loads just described were reached by an exercise protocol of progressively increasing intensities. It could be expected that tolerance times and physiological responses would be different if maximum effort were reached more abruptly. Since such conditions more closely resemble those encountered in the field, they were studied on 4 Ss (Tests 5 and 6). Table 4 illustrates data obtained during maximum work intensity which was applied suddenly and sustained as long as possible.

Maximum HR was different for these 4 Ss as compared to the total sample of $7 \mathrm{Ss}$ reported on in the previous section. The maximum values of 169 beat $/ \mathrm{min}$ 


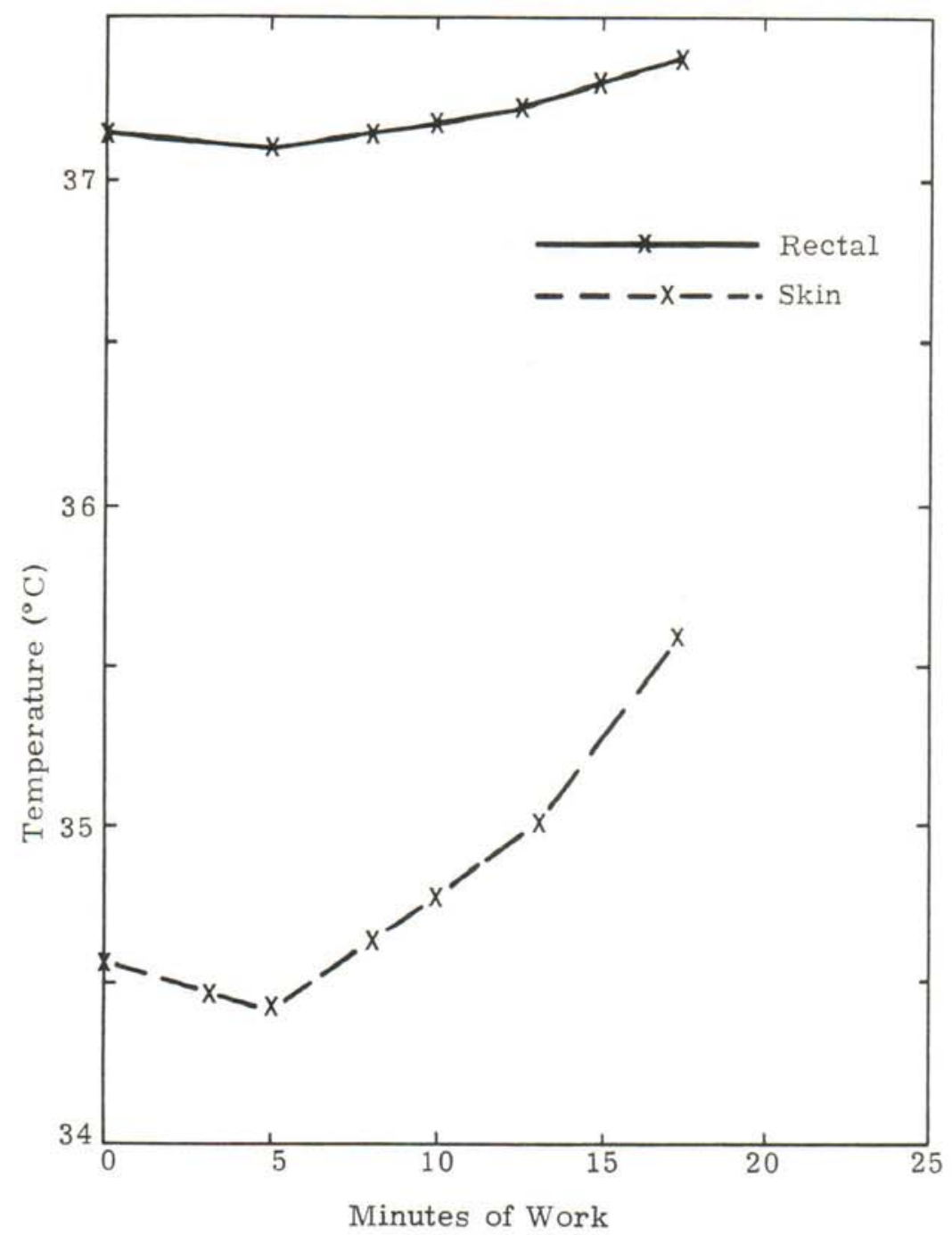

FIG. 5 - Time courses of skin and rectal temperatures during progressive, maximum effort while dressed in VBC.

with the VBC and 173 beat $/$ min without it reflect the approximate maximum HR obtained for these individuals during earlier testing, i.e., $172 \mathrm{bpm}$.

Maximum $V$ also agreed fairly well with earlier measurements as the means were $157 \mathrm{l} / \mathrm{min}$ without the $\mathrm{VBC}$ as compared to $164 \mathrm{l} / \mathrm{min}$ with it. Thus the differences in both $\mathrm{HR}$ and $\mathrm{V}$, were negligible which could be expected since the work intensity under both test conditions was identical and maximal. 


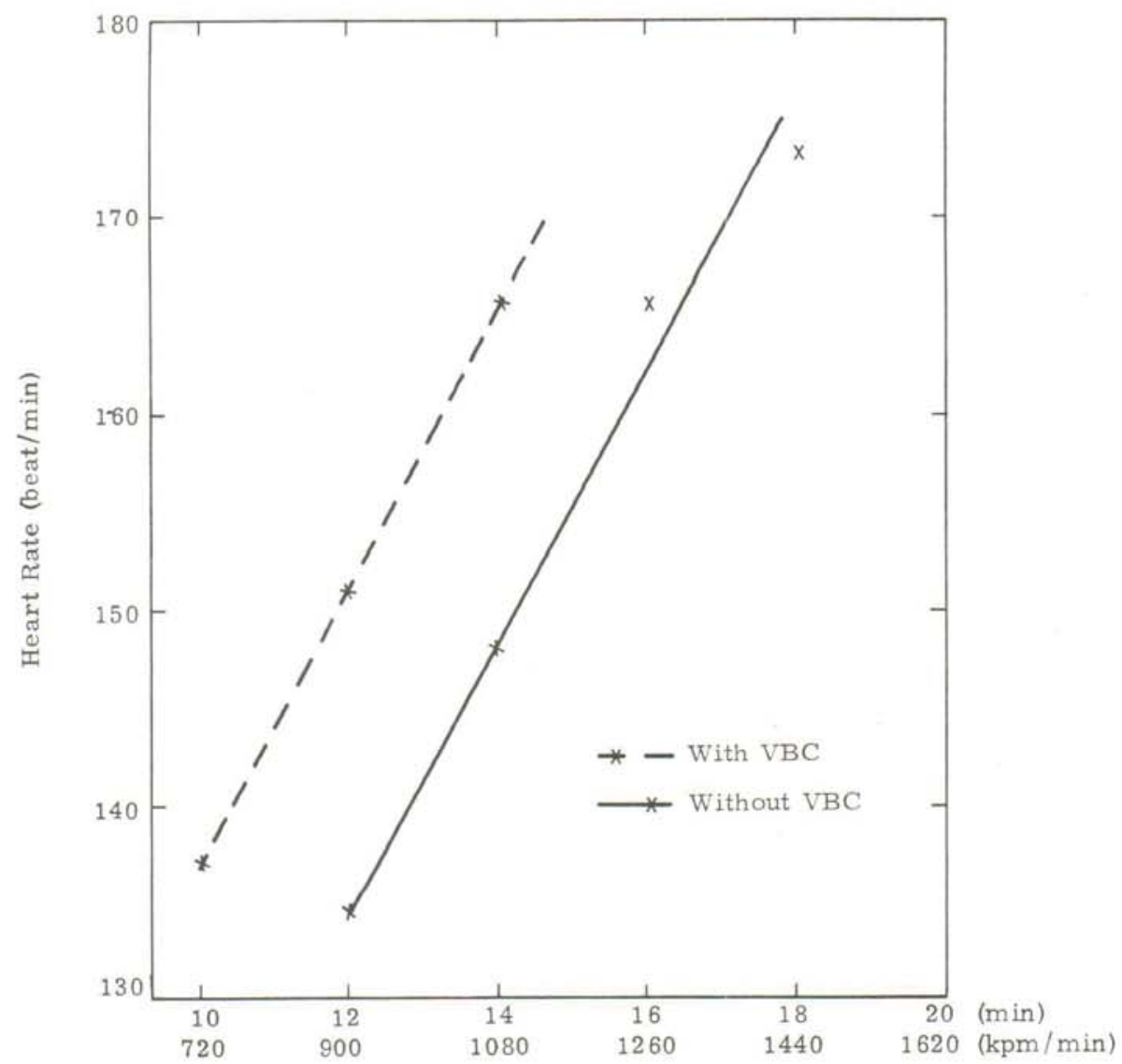

FIG. 6 - Heart rate response during different stages of the progressive, maximum test.

Mean maximai $\mathrm{V}_{\mathrm{O}_{2}}$ was slightly in excess of the maxima obtained previously during the progressive exercise tests. Mean $\mathrm{V}_{\mathrm{O}_{2}}$ for the test period was 100 to $102 \%$ under both test conditions. After 2 minutes of work, $\mathrm{V}_{\mathrm{O}}$, was 93 to $96 \%$ of maximum. At termination of the exercise, $\mathrm{V}_{\mathrm{O}_{2}}$ had risen to $110^{\circ} \%$ of maximum without the VBC as compared to $104 \%$ with the VBC. Again the reduced aerobic capacity while wearing the $\mathrm{VBC}$ is explained by reduced blood flow to the working muscles. For the same reason, the anaerobic contribution to the total energy demand is increased which results in accumulation of lactic acid sooner and at a faster rate; this could have caused the reduction in tolerance time from 11 to 7.5 minutes. 
TABLE 4

Maximal data recorded during maximal effort attained suddenly (mean $\neq$ S.D.)

\begin{tabular}{|c|c|c|c|}
\hline Variable & Without VBC & With VBC & $\begin{array}{c}\text { Difference } \\
(\text { (ii) }\end{array}$ \\
\hline Time, min & $11.0 \pm 0.82$ & $7.5=0.58$ & -32 \\
\hline Power, $\mathrm{kpm} / \mathrm{min}$ & $1350 \div 232$ & $1350=232$ & 0 \\
\hline Total work, kpm & $14.4=2.4$ & $10.0=1.1$ & -31 \\
\hline $\mathrm{V}_{\mathrm{O}_{2}}$ mean, $1 / \mathrm{min}$ & $3.30=0.42\left(102^{\circ} \%\right)^{*}$ & $3.23=0.40\left(100^{\circ} \circ\right)$ & -2 \\
\hline $\mathrm{V}_{\mathrm{O}_{2}} 2-\mathrm{min}, 1 / \mathrm{min}$ & $3.02=0.41\left(93^{\circ} \%\right)$ & $3.10=0.37\left(96^{\circ} w\right)$ & 3 \\
\hline $\mathrm{V}_{\mathrm{O}_{2}}$ final, $1 / \mathrm{min}$ & $3.55 \pm 0.45\left(110^{\circ} \mathrm{v}\right)$ & $3.36 \pm 0.56\left(104^{\circ} \cdot \omega\right)$ & -5 \\
\hline $\mathrm{HR}$, beat/min & $172.7 \pm 8.1$ & $168.7 \pm 9.1$ & -2 \\
\hline $\mathrm{V}, \mathrm{l} / \mathrm{min}$ & $156.9 \pm 31.0$ & $163.9=17.4$ & 4 \\
\hline
\end{tabular}

$\mathrm{V}_{\mathrm{O}_{2}}$ in pereent of maximal $\mathrm{V}_{\mathrm{O}_{2}}$ as determined during progressive maximal effort without $\mathrm{VBC}_{\mathrm{n}}$

Effects of VBC on prolonged submaximal work

Since most work tasks are of long duration and since continuous heat storage can be expected during prolonged activity while wearing imprevious clothing, physiological responses to work at about $60 \%$ of aerobic capacity (tests 3 and 4 ) were assessed. Results are reported in Tables 5 and 6.

TABLE 5

Time courses of selected variables during prolonged submaximal work at $60^{\circ} \mathrm{w}$ intensity (some data extra - or intrapolated).

\begin{tabular}{|c|c|c|c|c|c|c|c|c|c|}
\hline \multirow{2}{*}{ Variable } & \multicolumn{9}{|c|}{ Minutes of work } \\
\hline & 0 & 10 & 20 & 30 & 40 & 60 & 80 & 100 & 120 \\
\hline \multicolumn{10}{|c|}{ Without VBC (Test III) } \\
\hline$V_{O_{2}}, 1 / \min$ & 0.29 & & 1.74 & & 1.84 & 1.84 & 1.93 & 1.98 & 2.04 \\
\hline${ }_{0} \max$ & 9.3 & & 56.1 & & 59.3 & 59.3 & 62.3 & 63.9 & 65.8 \\
\hline $\mathrm{HR}$, beat $/ \mathrm{min}$ & 66 & & 132 & & 140 & 149 & 156 & & \\
\hline OP, ml/beat & 4.4 & & 12.6 & & 13.5 & 12.7 & 12.4 & & \\
\hline $\mathrm{V}, \mathrm{I} / \mathrm{min}$ & 13.1 & & 57.7 & & 60.2 & 62.5 & & & \\
\hline VEQ & 43.8 & & 32.6 & & 32.8 & 34.1 & & & \\
\hline \multicolumn{10}{|c|}{ With VBC (Test V) } \\
\hline $\mathrm{V}_{\mathrm{O}_{2}}, 1 / \min$ & 0.36 & 1.76 & 1.86 & 2.00 & 2.04 & & & & \\
\hline${ }_{0} \max$ & 11.6 & 56.8 & 60.0 & 64.5 & 65.8 & & & & \\
\hline HR, beat/min & 69 & 138 & 157 & 176 & & & & & \\
\hline OP, ml/beat & 5.2 & 14.0 & 14.5 & 14.2 & 13.2 & & & & \\
\hline $\mathrm{V}, 1 / \mathrm{min}$ & 17.3 & 68.3 & 69.4 & 80.5 & 83.3 & & & & \\
\hline VEQ & 47.5 & 40.5 & 39.0 & 38.9 & 41.3 & & & & \\
\hline
\end{tabular}


TABI.E 6

Selected mean data from prolonged submaximal work

\begin{tabular}{|c|c|c|c|}
\hline \multirow{2}{*}{ Variable } & \multirow{2}{*}{ Unit } & \multicolumn{2}{|c|}{$60^{\circ}$ of maximum } \\
\hline & & Without VBC & With VBC \\
\hline Power output & $\mathrm{kpm} / \mathrm{min}$ & 780 & 780 \\
\hline Exercise time & $\min$ & $101^{\circ}$ & 39 \\
\hline Total work & $\mathrm{kpm} \times 10^{-3}$ & 75 & 27 \\
\hline Mean HR & beat $\mathrm{min}$ & $139^{*}$ & 159 \\
\hline Terminal HR & beat $\min$ & $160^{*}$ & 175 \\
\hline
\end{tabular}

- This figure includes the arbirrary termination of 4 subjects at $120 \mathrm{~min}$

\section{Energy consumption}

Energy consumption relative to maximum ( $\max \mathrm{V}_{\mathrm{O}_{2}}=3.10 \mathrm{l} / \mathrm{min}$ ) were $61 \%$ and $63 \%$ respectively, which may be considered identical.

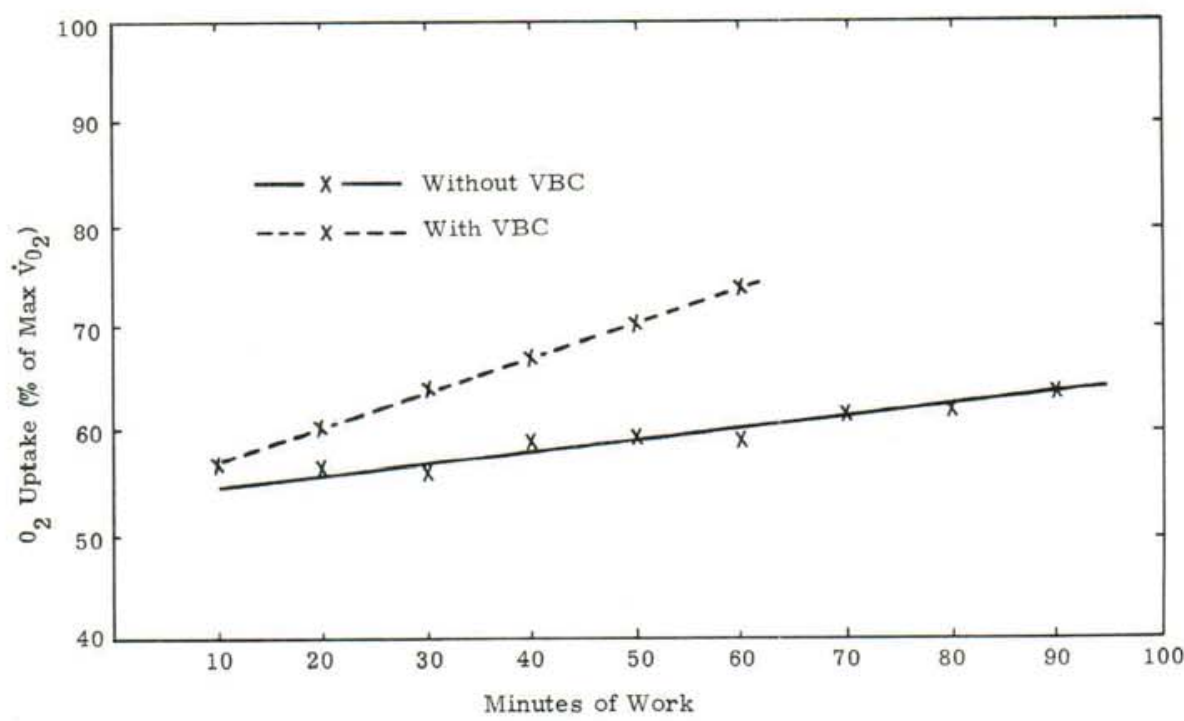

FIG. 7 - Oxygen uptake during prolonged work at $60^{\circ}$ intensity.

Figure 7 shows the time courses of $\mathrm{V}_{\mathrm{O}}$, at a fixed mean power load of 780 $\mathrm{kpm}$ min. $\mathrm{V}_{\mathrm{O}_{2}}$ increased steadily, i.e., mechanical efficiency was continually declining, during both work conditions. One factor with influence in this respect is progressing fatigue, resulting in mobilization of less efficient auxiliary muscles. The slope of the $\mathrm{V}_{\mathrm{O}_{2}}$ response with time was much greater when the VBC was worn. 
The reduction in work time caused by the VBC cannot be accurately determined since the work sessions without the VBC at $60 \%$ intensity were However, even so, before exhaustion (after 2 hours) in four of the seven $\mathrm{S}$ s. minutes when the VBC was time decreased from $101 \pm 25$ minutes to $39 \pm 20$ time would, in effect, have been considable 6 ). This $63 \%$ reduction in tolerance to the cardiovascular limits, considerably greater had all tests been continued identical in each case.

The dramatic reduction in sustainable work time resulted in reductions in total work performed of $64 \%$ at the $60 \%$ level (Table 6). Thus, the effect of the $\mathrm{VBC}$ on work output was considerable. With the VBC, total work was 27000 $\mathrm{kpm}$ at $60 \%$ intensity as compared to $75000 \mathrm{kpm}$ without the VBC.

\section{Heart rate}

Figure 8 illustrates the time course of the average HR for all seven Ss during work at an intensity of $60 \%$ maximum. Both without and with the VBC, HR climbed continually so that no steady state was achieved. This is consistent responses are widel the subject of prolonged work. The slopes of the HR VBC. This resulted in he attainmed much faster during work in the under conditions of impaired evaporation was discontinued after 2 hours for los. Since work without the VBC under control conditions.

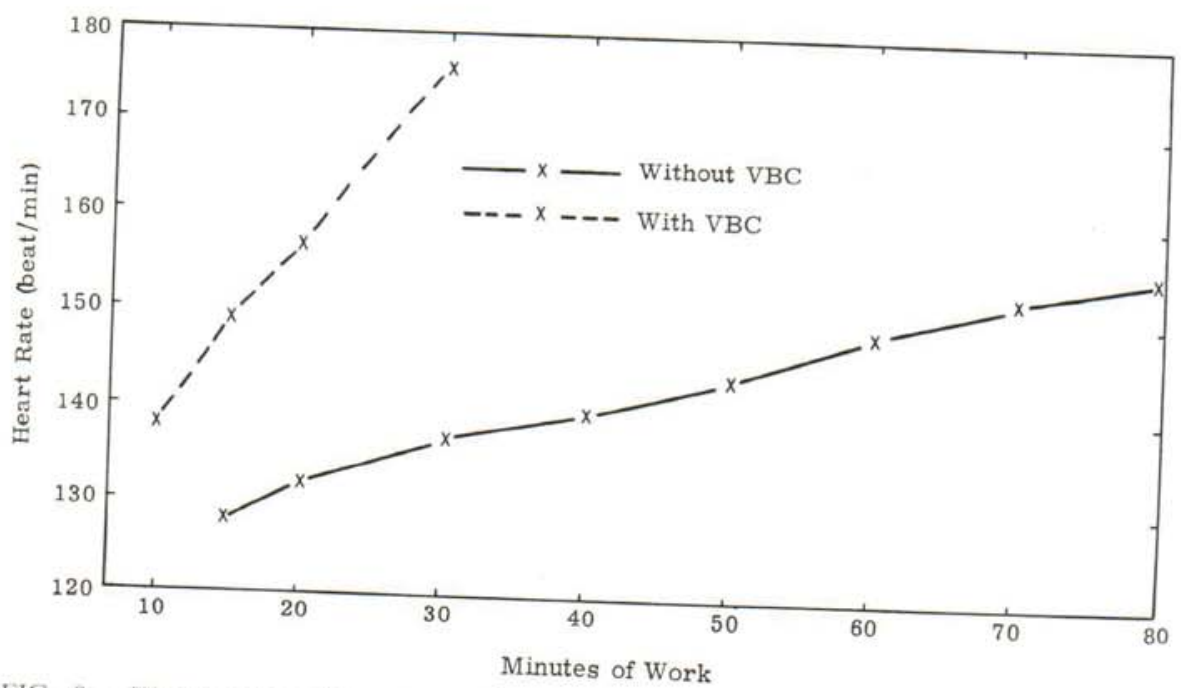

FIG. 8 - Time courses of heart rate during prolonged work at $60^{\circ} \mathrm{o}$ intensity: 
The vigorous HR response to work of the Ss wearing the VBC is explained by increased blood flow requirements in the skin when heat dissipation is curtailed. Since stroke volume (SV) reaches maximum very quickly, continued increase in cardiac output (Q) must be achieved through elevations in HR. As maximum HR is approached, no further increase in $Q$ is possible and, e increased blood flow to the skin can be maintained onl at the expense of muscle perfusion. The ensuing muscular ischemia $\left(\mathrm{O}_{2}\right.$ lack) causes a rapid deterioration in work performance and tolerance time.

\section{Rectal temperature}

It has been found that "when environments are compared. . . the rate of rise of body temperature is a linear function ${ }^{2}$." Figure 9 illustrates the time courses of mean rectal temperatures $\left(T_{r}\right)$ during work at $60 \%$ intensity with and without the VBC. As may be seen, temperature did increase almost rectilinearly with time, the slopes being considerably steeper with the VBC.

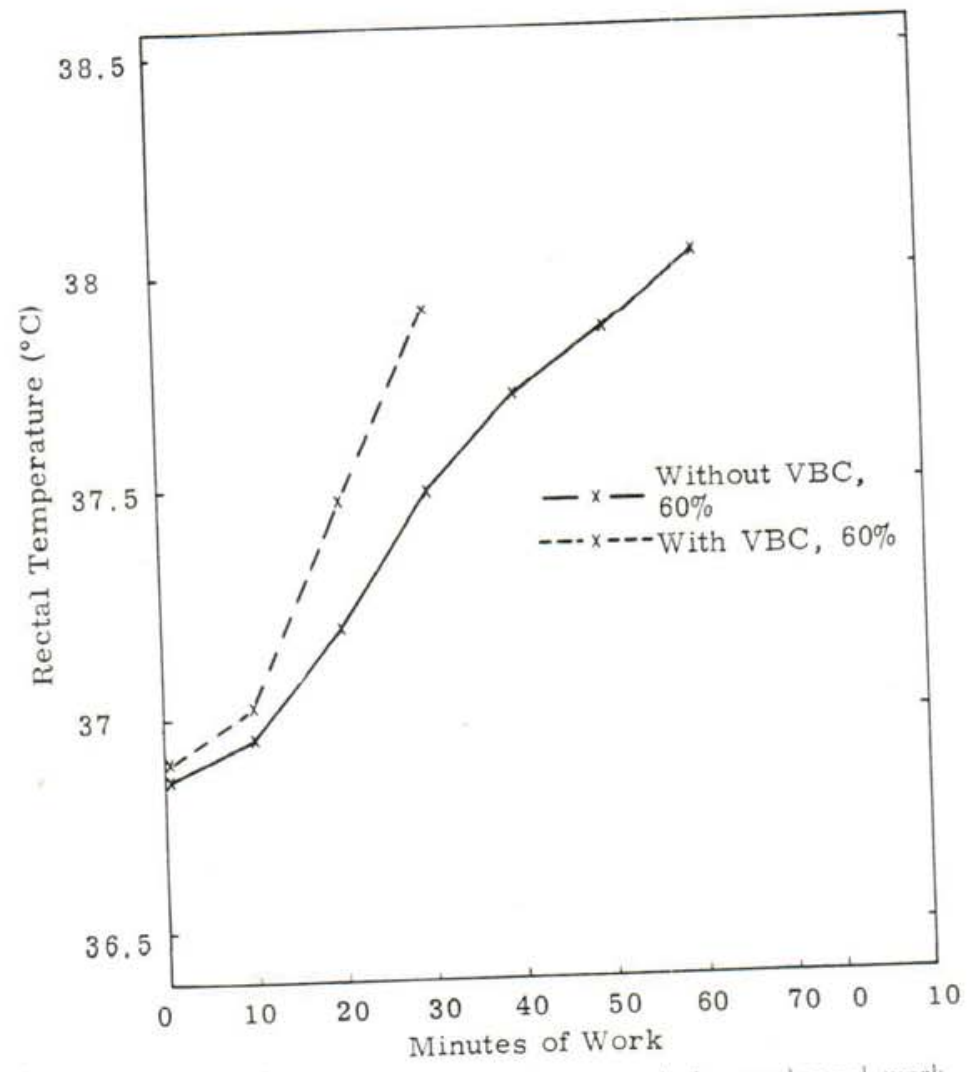

FIG. 9 - Time courses of rectal temperature during prolonged work. 
When prolonged work is performed at moderate work loads, it has been shown to be possible to "predict rectal temperature response to work and heat on the basis of heart rate 5 ." Figure 10 illustrates the relationships between HR and $\mathrm{T}_{\mathrm{r}}$. Beyond an HR of $140 \mathrm{beat} / \mathrm{min}$, correlations appear to be quite linear for the two test conditions. At that point, $\mathrm{T}_{\mathrm{r}}$ was $37.7^{\circ} \mathrm{C}$ at $60^{\circ} \mathrm{o}$ intensity without the $\mathrm{VBC}$ as compared to $37.1 \mathrm{C}$ with the $\mathrm{VBC}$. This supports the contentions that (1) the limiting factor to working under extreme heat loads is not core temperature, but rather an unfavorable distribution of blood flow, and (2) regardless of work intensity, at submaximal workloads, HR correlates well with rectal temperatures.

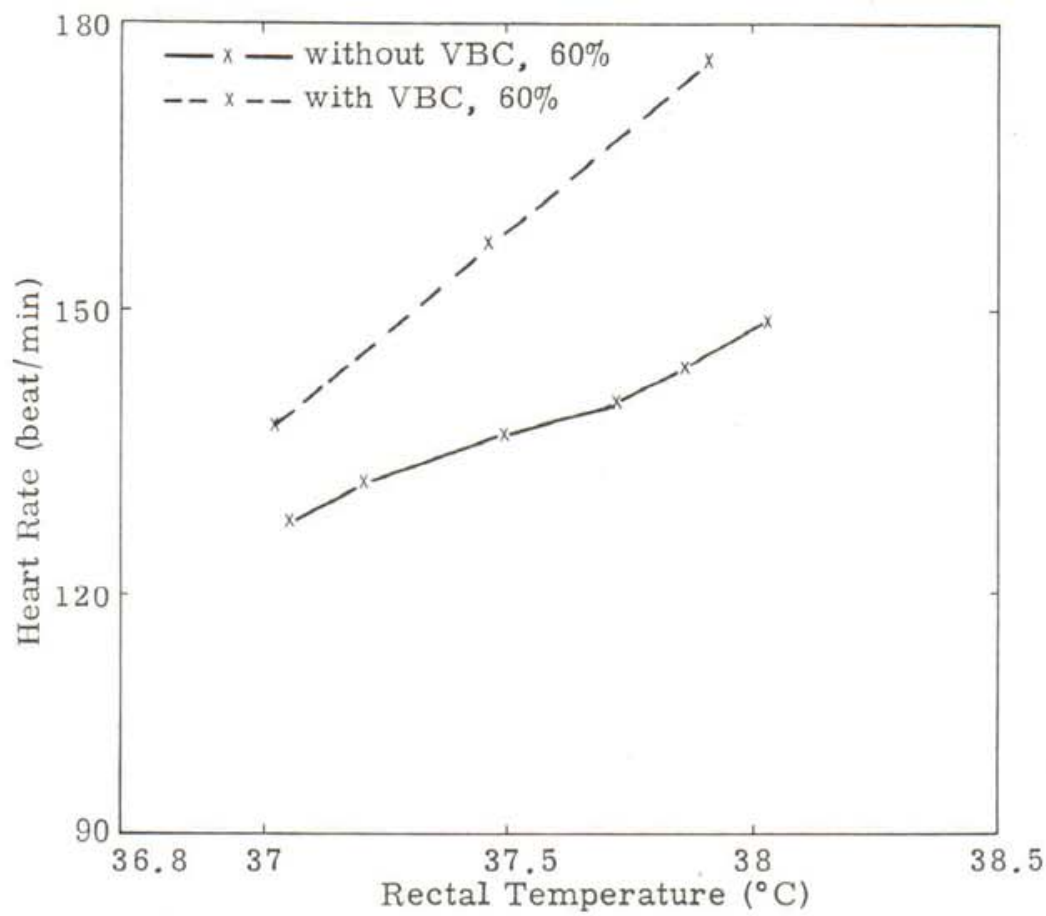

FIG. 10 - Rectal temperatures and heart rates during prolonged work.

\section{Skin temperature}

Figure 11 illustrates changes in mean skin temperature $\left(\overline{\mathrm{T}}_{\mathrm{s}}\right)$ with time while Ss were working at $60 \%$ relative intensity. Without the $\mathrm{VBC}, \overline{\mathrm{T}}_{\mathrm{s}}$ reached a plateau after 30 minutes of work. This steady state probably identified the thermal gradient between skin and ambient air required under the circumstances to maintain thermal equilibrium. On $\mathrm{Ss}$ wearing the VBC, $\overline{\mathrm{T}}_{\mathrm{s}}$ climbed rapidly from $34.2 \mathrm{C}$ to $37.0 \mathrm{C}$ within 30 minutes of work. 


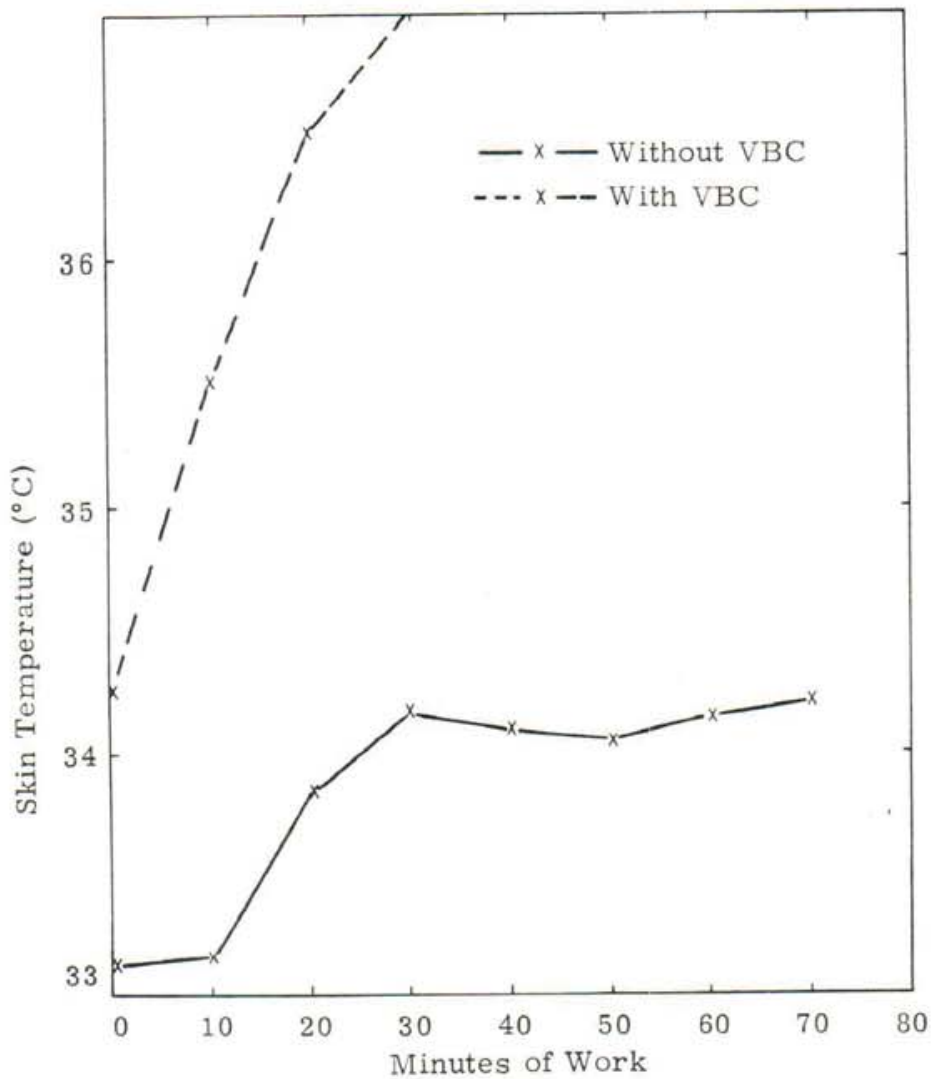

FIG. 11 - Responses in skin temperature during prolonged work at $60^{\circ} \mathrm{o}$ intensity.

Figure 12 shows the relationship between HR and $\overline{\mathrm{T}}_{\mathrm{s}}$. Obviously $\overline{\mathrm{T}}_{\mathrm{s}}$ cannot be used as a stress indicator under circumstances of unimpeded heat dissipation. However, with the VBC, there appears to be a close relationship between HR and $\bar{T}_{s}$. This is explained by the previously discussed phenomenon of redistribution of blood flow. Accumulation of heated blood in the skin would cause an elevation in $\bar{T}_{\mathrm{s}}$ just as the shift of blood from the working muscles results in increased $H R$. Therefore, $\bar{T}_{s}$ would seem to offer an acceptable alternative to $\mathrm{HR}$ as a stress indicator during prolonged work while the $\mathrm{VBC}$ is worn or in a hot and humid environment with severely curtailed evaporative heat loss ${ }^{4}$. 


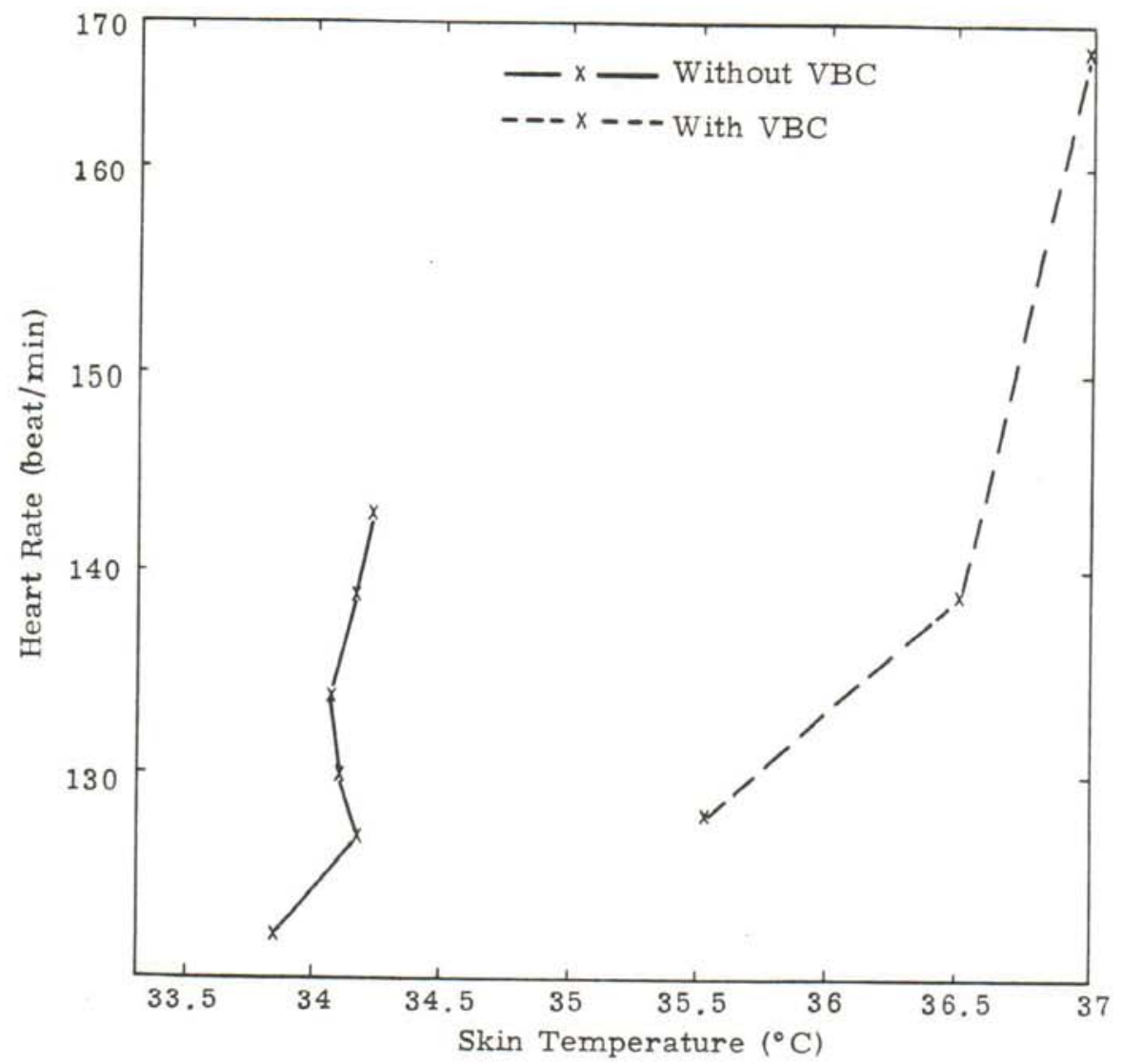

FIG. 12 - Relationships between heart rate and skin temperature during prolonged work at $60^{\circ}$. intensity.

\section{SUMMARY AND CONCLUSIONS}

The effects of VBC on work performance have been described in Section Methods and Procedures and in Section Results and Discussion. Subject safety did not.permit continuing the exercises to their final end point which would be disorientation and collapse. This is a definite possibility in any group performing maximum work in an impermeable suit. The probability of this occurrence would increase dramatically with increases in the WBGT index.

During rest, most body heat is dissipated through convection and radiation. However, during exercise, with increasing intensity and duration, evaporation becomes progressively more important in maintaining thermal equilibrium ${ }^{3}$. When evaporative heat loss is interfered with, heat storage occurs. When the air temperature approaches $33-35 \mathrm{C}$ the body ceases to lose heat through the 
mechanisms of convection and radiation. Therefore, the thermal model (see introduction) becomes

$$
\mathrm{M}+\mathrm{C}+\mathrm{R}-\mathrm{E}=+\mathrm{S} \text { (heat storage) }
$$

TABLE -

Summary of engineering data, progressive maximum vs square-wave maximum tests.

\begin{tabular}{|c|c|c|c|c|c|c|}
\hline \multirow[b]{2}{*}{ Time } & \multicolumn{3}{|c|}{ W ithout VBC } & \multicolumn{3}{|c|}{ With VBC. } \\
\hline & $\begin{array}{l}\text { Time } \\
\text { (min) }\end{array}$ & $\begin{array}{c}\text { Power } \\
(\mathrm{kpm} / \mathrm{min})\end{array}$ & $\begin{array}{c}\text { Total work } \\
\text { (kpm) }\end{array}$ & $\begin{array}{l}\text { Time } \\
\text { (min) }\end{array}$ & $\begin{array}{c}\text { Power } \\
(\mathrm{kpm} / \mathrm{min})\end{array}$ & $\begin{array}{c}\text { Total work } \\
\text { (kpm) }\end{array}$ \\
\hline $\begin{array}{l}\text { Progressive } \\
\text { maximum }\end{array}$ & 19.6 & 1600 & 15.100 & 17.4 & 1400 & 11.800 \\
\hline $\begin{array}{l}\text { Square-wave } \\
\text { maximum }\end{array}$ & 11.0 & 1350 & 14.400 & 7.5 & 1350 & 10.000 \\
\hline
\end{tabular}

Effects of VBC on maximal performance

Maximum performance was studied with two different protocols.

Progressive maximal effort

This test determines an individual's mavimal oxygen consumption $\left(\max \mathrm{V}_{\mathrm{O}_{2}}\right.$ ). Maximal $\mathrm{V}_{\mathrm{O}_{2}}$ is reached when an increas in work load fails to elicit a further increase in consumption. The differences were summarized in Table 5.

HR increased linearly with work intensity under both test conditions. Maximum HR were practically identical both with and without the VBC which validates the tests as being maximal (Figure 6). Rectal temperature change was minimal because of the brevity of work. HR appears to be the preferrable stress indicator under conditions of progressive, maximal work. The VBC caused an $11^{\circ}$ reduction in tolerance time as well as a $22^{\circ}$. decrease in total work.

Sudden maximal effort

It is possible that a task associated with time urgency would be completed more quickly if the worker(s) resort(s) to an all-out effort from the onset. The physiological effects of the VBC on such a work protocol were also observed during a square-wave maximal effort. This test profile differed from the aforementioned in that maximum effort was attained abruptly and thereafter sustained until exhaustion rather than reached through a progressive series of increasing work loads. Table 4 summarizes the results.

Tolerance time decreased, because of the VBC, by $32 \%$ (from 11 to $7.5 \mathrm{~min}$ ) which also resulted in a decrease in total work output of $31^{\circ}$ (from 14400 to $10000 \mathrm{kpm})$. Again, rectal temperature did not appear to be useful as a stress indicator in this case, so HR should be used for that purpose. Table 7 summarizes the difference between the two exercise protocols. 
The following observations seem valid: first, use of the VBC causes a significant decrease in tolerance time, power output, and total work accomplished when compared to identical tests without the VBC. Second, the percentage reduction in work tolerance while the VBC is worn appears to be about the same $(25 \%)$ regardless of the maximum work protocol (progressive or square-wave).

Effects of VBC on prolonged submaximal work

Most tasks are performed at a submaximal work level, especially if they require prolonged effort. There is considerable variation in the energy requirements of various activities. A work level of $60 \%$ of the subjects' maxima was selected for this study. This level provides sufficient time to reach a cardiovascular and metabolic steady state without the VBC while providing adequate stress to enable valid comparisons between the two clothing alternatives.

At the $60 \%$ submaximal level, the most obvious and significant differences between tests with and without the VBC were in the tolerance times and total work performed. Table 8 shows a $63 \%$ reduction in tolerance time and a $64 \%$ reduction in total work. These reductions would have been considerably greater had the tests without the VBC been continued to the cardiovascular limits of all subjects.*

TABLE 8

Selected variables from the $60^{\circ}$. submaximal tests.

\begin{tabular}{|c|c|c|c|c|}
\hline & $\begin{array}{l}\text { Tolerance time } \\
\text { (min) }\end{array}$ & $\begin{array}{l}\text { Total work } \\
\text { (kpm) }\end{array}$ & $\begin{array}{c}\mathrm{HR} \\
\text { (at termination) }\end{array}$ & Mean HR \\
\hline Without VBC & $101^{*}$ & 75000 & 160 & 139 \\
\hline With VBC & 39 & 27000 & 175 & 159 \\
\hline
\end{tabular}

In addition to the decreases in tolerance, total work and work intensity, various physiological measurements also demonstrated the added stress that the VBC produces.

Heart rate

At $60 \%$ of maximum work load, there was a marked difference in the rate of progression of the HR. With the VBC the test was terminated in 30 minutes at an average $H R$ of 175 while without the $V B C$ it was terminated at $H R=160$ after 2 hours (Figure 8).

As previously noted, HR is an excellent index of physical stress, especially. during aerobic activities. In this case, for each minute of work, HR increased an average of 3.5 beat $\mathrm{min}$ with the $\mathrm{VBC}$ as compared to 0.75 beat $/ \mathrm{min}$ without it.

The most likely explanation of the more rapid rise in $\mathrm{HR}$ with the $\mathrm{VBC}$ is the increase in blood flow to the skin at the expense of muscular perfusion.

*Tests with four of the seven subjects were arbitrarily terminated at 120 min. See Table 6. 


\section{Rectal temperature}

It has been found that "when environments are compared... the rate of rise of body temperature is a linear function ${ }^{2}$." Rectal temperature $\left(\mathrm{T}_{\mathrm{r}}\right)$, like heart rate, increased at a steeper rate with the VBC (Figure 9). With the VBC, it increased $0.22^{\circ} \mathrm{C}$ every 5 minutes as compared to $0.11^{\circ} \mathrm{C}$ without the VBC. From another perspective, HR rose by 21 beat/min per $C$ elevation in $T_{r}$ without the VBC as compared to 42 beat $\mathrm{min}$ with VBC.

When testing is performed at moderate work loads, it has been shown to be possible to "predict rectal temperature response to work and heat on the basis of heart rate 5 ." Figure 10 illustrates this relationship.

\section{Skin temperature}

With the VBC at $60^{\circ}$ work intensity, there is a continuous, sustained increase in $\overline{\mathrm{T}}_{5}$ of almost $4{ }^{\circ} \mathrm{C}$ when compared to the baseline $\overline{\mathrm{T}}_{\mathrm{S}}$ without the VBC. $\mathrm{By}$ comparison, without the VBC, there was a rise of slightly more than $1 \mathrm{C}$ at 30 minutes and then a plateau ("steady state") was maintained (Figure 11).

Figure 12 shows the relationship between $H R$ and $\bar{T}_{\mathrm{s}}$. With the VBC, there is a rather close relationship between the two variables. Therefore, $\overline{\mathrm{T}}_{\mathrm{S}}$ may offer an alternative to HR as a stress indicator during prolonged work in the VBC, i.e., in a hot and humid environment with curtailed evaporative heat loss. Iampietro and Goldman ${ }^{4}$ have shown that rapid changes in skin temperatures during work in hot, humid environments may be a good predicator of tolerance times.

This increase in skin temperature can only be explained by a large cutaneous shunting of blood under conditions of curtailed heat dissipation. This must be at the expense of perfusion of a large portion of the remainder of the body:

\section{Summary of engineering data}

Table 9 summarizes the engineering data for three of the test situations. In all three, the use of the VBC imposes significant limitations on tolerance time, on

TABLE 9

Summary of engineering data by test and type of clothing.

\begin{tabular}{|c|c|c|c|c|}
\hline Test & Suit & $\begin{array}{l}\text { Time } \\
(\mathrm{min})\end{array}$ & $\begin{array}{c}\text { Power } \\
(\mathrm{kpm} / \mathrm{min})\end{array}$ & $\begin{array}{c}\text { Total work } \\
\text { (kpm) }\end{array}$ \\
\hline \multirow{3}{*}{ Progressive maximum } & Without VBC. & 19.6 & 1600 & 15100 \\
\hline & W ith VBC & 17.4 & 1400 & 11800 \\
\hline & Decrease due to VBC $\left({ }^{\circ} \circ\right)$ & 11 & 13 & 22 \\
\hline \multirow{3}{*}{ Square-wave maximum } & Without VBC & 11 & 1350 & 14400 \\
\hline & $W$ ith $V B C$ & 7.5 & 1350 & 10000 \\
\hline & Decrease due to VBC $\left({ }^{\circ} " 1\right)$ & 32 & - & 31 \\
\hline \multirow{3}{*}{$60 \%$ submaximum } & Without VBC & $101^{*}$ & 780 & 75000 \\
\hline & $W$ ith $V B C$ & 39 & 780 & 27000 \\
\hline & Decrease duc to VBC ( $/ \mathrm{o})$ & 61 & - & 64 \\
\hline
\end{tabular}

- Tests with four of the seven subjects were arbitrarily terminated at $120 \mathrm{~min}$. See Table 6. 
power output, and on total amount of work performed. In addition to those limitations, Figure 13 summarizes the time courses for the selective stress variables of $H R, T_{r}$, and $\bar{T}_{s}$.

It is apparent that not only does the use of the VBC decrease total work output and work tolerance time, it also imposes on the organism a physiological stress of considerable magnitude. This stress cannot be ignored in any work situation requiring a work effort probably in excess of $40 \%$ of maximum intensity:
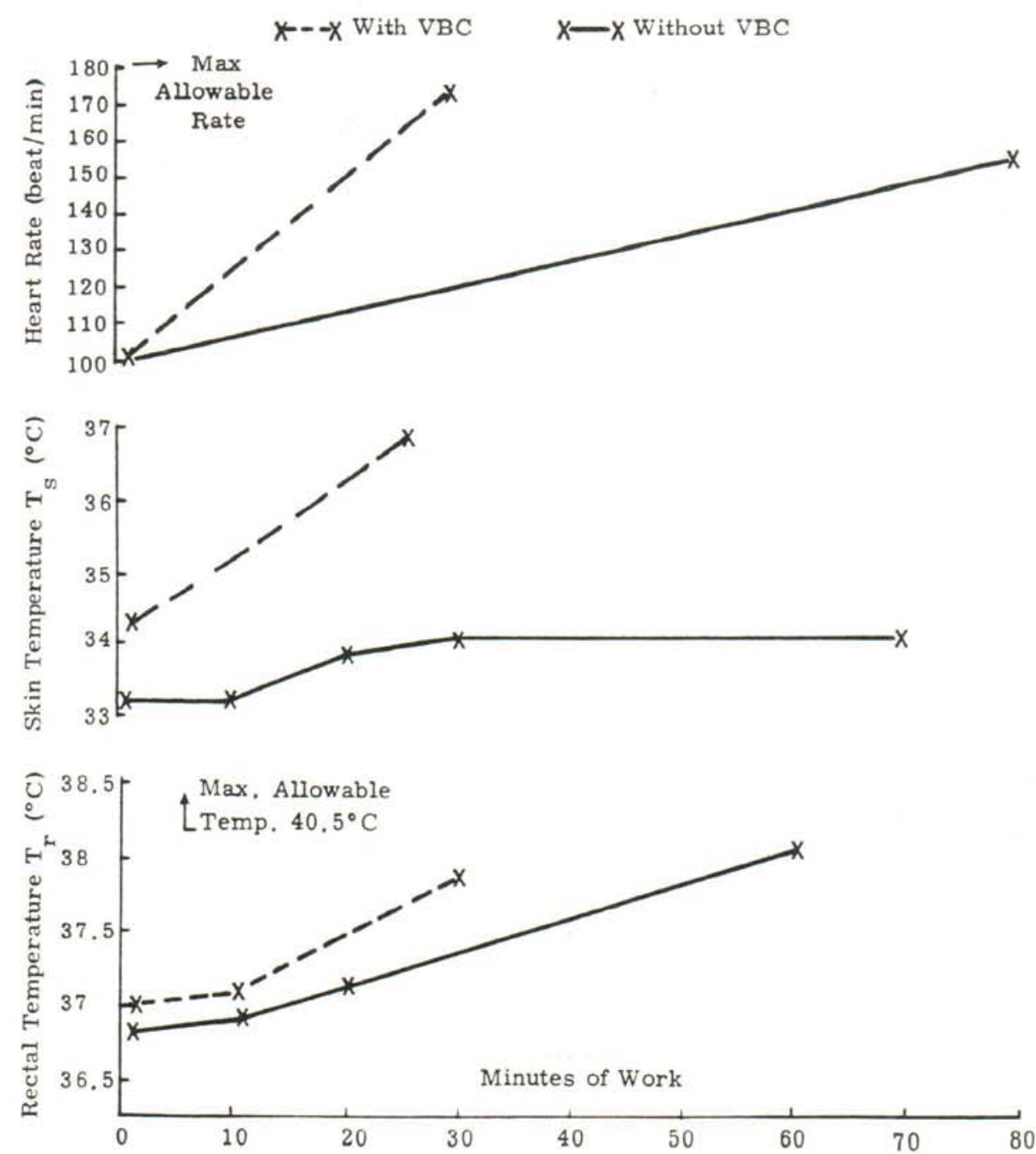

FIG. 13 - Summary of time courses for heart rate, skin temperature and rectal temperature during prolonged work at $60^{\circ} \mathrm{n}$ intensity. 


\section{REFERENCES}

1. Astrand, P.O. Work Tests with the Bicjcle Ergometer, Operating Manual, A.B. Cykelfabriken Monark, Varberg, Sweden.

2. Blockley, IV.I ., McCutciban, J.IW., Lyman, J. and Taylor, C.L. Human tolerance for high temperature aircraft environments. J. Appl. Physiol., 31 (1971) 515-522.

3. Goldman, R.F. Clothing Design for Comfort and Work Performance in Extreme Thermal Environments, N.Y. Academy of Science Transactions, Ser. 2, 36 (1974) 531-544.

4. Iampietro, P.F. and Goldman, R.F. Tolerance of men working in hot humid environments. J. Appl. Physiol., 20 (1965) 73-76.

5. Kamon, L. and Belding, H.S. Heart rate and rectal temperature relationships during work in hot humid environments. J. Appl. Physiol., 31 (1971) $472-477$.

6. Martin, H. de $\mathrm{V}$. and Calloway, S. An evaluation of the heat stress of a protective face mask. Ergonomics, 17 (1974) $221-231$.

7. Minard, Capt, D. (M/C, LSMC) Prevention of Heat Casualties in Marine Corps Recruits, 1955-1960, Research Report No. 4, Contract No. MR 005.01-0001.01, Naval Medical Research Institute, Bethesda, Maryland, 1961.

8. Yaglou, C.P. Habitability Studies in Climatic Extremes, Annual Report No. 9, to the Commission on Environmental Hygiene, Armed Forees Epidemiological Board, 1956. 